\title{
The effect of insstructions on judgment of the Muiller-Lyer illusion with normal and haptically mediated visual inspection
}

\author{
JOHN EAGLEN AND BARRY KIRKWOOD 1 \\ UNIVERSITY OF AUCKLAND
}

\begin{abstract}
An experiment with the Muller-Lyer figure is reported in which variation in instructions resulted in a change in the magnitude of the visual illusion under normal viewing conditions. Variation in instructions did not, however, have a differential effect on the magnitude of the illusion when $S s$ inspected the figure by means of a point source of light attached to one fingertip. These results are equivalent to differences found between the effect of instructions on visual and haptic illusions using the same illusion figure and support the view that variation in inspection patterns rather than differences in higher processing of sensory input might account for differences between the two modalities.
\end{abstract}

It is now well established that many "optical" illusions have counterparts in other sense modalities, in particular the tactile or haptic modality. In many respects, the haptic illusions are affected in the same ways by the same variables that influence the visual illusions, e.g., Rudel and Teuber (1963) on extended practice with the Müller-Lyer (ML) figure and Over (1966) on effects of varying the included angle of the obliques of the ML figure. Some variables, however, have different effects upon the visual and haptic illusions. For example, visual judgment of the magnitude of the ML illusion changes with S's age (Piaget, 1961), while the haptic ML is unaffected by age (Over, 1967). Instructions to judge "apparent" length of the axis of the ML figure generally result in greater visual illusions than instructions to judge "objective" length (Bates, 1923; Day, 1962). A recent study by Over (1968) verified the instruction effect for visual illusions but failed to find a corresponding effect on the haptic illusion.

Over (1968) suggests that differences between visual and haptic judgments of the same geometric illusion may reflect different search patterns used in each case, rather than physiological differences in processing spatial information by each sense. The present study tests this hypothesis by replicating Over's (1968) experiment, but substituting for haptic inspection a restricted visual condition in which visual inspection of the ML figure is forced to conform to a haptic search pattern.

\section{METHOD}

\section{Subjects}

Ss were 32 volunteers from a first-year psychology class. They had not received formal instruction on illusions at time of testing.

\section{Apparatus}

The ML figure was painted on a matt black board measuring $35 \times 10 \mathrm{~cm}$. A white line, $20.6 \mathrm{~cm} \times 3 \mathrm{~cm}$, ran down the center, terminating in 60-deg arrowheads each $9 \mathrm{~cm}$ long. A thin black metal sheet fitted over the board like the cursor of a slide rule and carried a white center line and arrowhead to complete the figure. The cursor could be moved by S. For half the Ss in each group, the outward-pointing fixed arrowhead was on S's left on all trials, and for the others on S's right. Half of each group of Ss made judgments with the movable arrowhead initially set $2.7 \mathrm{~cm}$ to the left of midposition and vice versa.

All testing was carried out in a light-proof, sound-proof chamber with matt black interior walls. The $S$ sat at a table with a uniform Masonite surface on which the apparatus was placed. For trials under normal viewing conditions, the room was dimly lit by an incandescent lamp that gave the white portions of the test figure a luminance of $0.01 \mathrm{~mL}$ as measured with an S.E.I. photometer.

For testing under the restricted condition, the room was dark, the only source of light being a miniature lamp and optical system taped to S's index finger. When held $1 \mathrm{~cm}$ above the ML figure, this projected a circular spot of $1 \mathrm{~cm}$ diam, giving a luminance of $0.01 \mathrm{~mL}$ to the white line.

\section{Procedure}

Each $S$ made seven judgments under normal viewing conditions and seven restricted, the order of conditions being counterbalanced over Ss. The first trial was treated as a practice run. Sixteen Ss received "objective" instructions and 16 "apparent" instructions.

Each $S$ was given both criterion and procedural instruction on a typewritten sheet. Procedural instructions were the same for all Ss and were further explained and demonstrated where necessary suring the practice trial. The criterion instructions were not supplemented, but were shown to $S$ again if he was uncertain of his task.

The "objective" instruction was: "Set the middle arrowhead so that its center is exactly midway, as would be measured by a tape measure, between the centers of the outer arrowheads. Try to be as accurate as you can."

The "apparent" instruction was: "Set the middle arrowhead so that its center looks to you to lie half-way between the centers of the outer arrowheads."

Under the restricted condition, no limit was set to the number of times the figure could be traced with the light, but wherever part of an arrowhead was illuminated $S$ was required to trace the entire arrowhead. Shade 6 welding goggles were worn by $S$ between trials while $E$ recorded settings. No $S$ was given information about the accuracy of his settings.

\section{RESULTS}

Table 1 shows the mean and standard deviations of the settings of the "apparent" and "objective" instruction groups under both normal and restricted conditions and for each order of judgment: normal before restricted (n-r) and restricted before normal (r-n).

The mean illusion, measured as distance (in centimeters) at which the center arrowhead deviated from the midposition, under normal conditions $(1.18 \mathrm{~cm})$ does not differ from that obtained under

Table 1

Miiller-Lyer Illusion Magnitudes Displacement from Midposition (cm)

\begin{tabular}{lccccc}
\hline & & \multicolumn{2}{c}{ Objective } & \multicolumn{2}{c}{ Apparent } \\
\cline { 3 - 5 } & Judgment & Mean & SD & Mean & SD \\
\hline \multirow{2}{*}{ Normal } & $\mathrm{n}-\mathrm{r}$ & 1.26 & 0.39 & 1.09 & 0.39 \\
& $\mathrm{r}-\mathrm{n}$ & 1.28 & 0.40 & 1.10 & 0.46 \\
Restricted & $\mathrm{n}-\mathrm{r}$ & 1.22 & 0.31 & 1.04 & 0.47 \\
& $\mathrm{r}-\mathrm{n}$ & 1.14 & 0.65 & 1.28 & 0.51 \\
\hline
\end{tabular}


restricted conditions $(1.17 \mathrm{~cm})$, taking the limited precision of the apparatus into account.

Separate two-way analyses of variance for each condition were carried out to test for effects of instruction or orders. The effect of instructions was found to be significant $[F(1,188)=9.49, p<.01]$ for normal conditions, although the effect of instructions regarded as "objective" is to increase the illusory effect and not, as expected, to decrease it. Instructions have no effect on judgments in restricted conditions. Order and interaction effects were not significant at the $p<.05$ level under either normal or restricted conditions.

\section{DISCUSSION}

The present study verifies the notion that instructions influence the judgment of the ML illusion under normal visual inspection conditions, although there is no obvious reason why the difference between "objective" and "apparent" instructions shown above is in the opposite direction to that found by Over (1968). On the other hand, Over found that instructions had no effect on haptic judgments of the ML figure. The present experiment shows that instructions also have no effect when there is imposed on visual inspection a search pattern typical of the tactile sense. This indicates that the difference Over found between the visual and haptic modes is largely dependent upon the type of scanning used and the mode of presentation of the stimulus, rather than on any difference in the higher processing of input from the two senses. The demonstrated importance of eye movements and scanning methods in determining decrement in the ML illusion with repeated trials (Day 1962; Festinger et al, 1968; Burnham, 1968) also supports this view. One generalization that might be made from all these findings can be stated as follows: Studies comparing form perception between modalities, individuals, or species should consider the possibility that even when stimuli are equivalent inspection patterns may differ markedly.

\section{REFERENCES}

BATES, M. A study of the Müller-Lyer illusion with special reference to paradoxical movement and the effect of attitude. American Journal of Psychology, 1923, 34, 46-72.
BURNHAM, C. Decrement of the Müller-Lyer illusion with saccadic and tracking eye movements. Perception \& Psychophysics, $1968,3,424-426$.

DAY, R. H. The effects of repeated trials and prolonged fixation on error in the Müller-Lyer figure. Psychological Monographs, 1962, 76(Whole No. 533).

FESTINGER, L., WHITE, C. W., \& ALLYN, M. $R$. Eye movements and decrement in the $M$ üller-Lyer illusion. Perception \& Psychophysics, 1968, 3, 376-382.

OVER, R. A comparison of haptic and visual judgments of some illusions. American Joumal of Psychology, 1966, 79, 590-595.

OVER, R. Haptic judgment of the Muller-Lyer illusion by subjects of different ages. Psychonomic Science, 1967, 9, 365-366.

OVER, $R$. The effect of instructions on visual and haptic judgment of the Müller-Lyer illusion. Australian Joumal of Psychology, $1968,20,161-164$.

PIAGET, J. Les mechanismes perceptifs. Paris: Presses Universitaires de France, 1961.

RUDEL, R. G., \& TEUBER, H. L. Decrement of visual and haptic Müller-Lyer illusion on repeated trials: A study of cross-modal transfer. Quarterly Journal of Experimental Psychology, 1963, 15, 125-131.

\section{NOTE}

1. Address: Department of Psychology, University of Auckland, Auckland, New Zealand.

(Accepted for publication October 27, 1969.) 